\title{
A nationwide population-based study of the familial aggregation of Type 1 (insulin-dependent) diabetes mellitus in Denmark
}

\author{
F. Pociot ${ }^{1}$, K. Nørgaard ${ }^{1}$, N.Hobolth ${ }^{2}$, O. Andersen ${ }^{3}$, J. Nerup $^{1}$ and the Danish Study Group of Diabetes in Childhood* \\ ${ }^{1}$ Steno Diabetes Center, Gentofte, Denmark \\ ${ }^{2}$ Department of Paediatrics, Kolding Hospital, Kolding, Denmark \\ ${ }^{3}$ Department of Paediatrics, Næstved Hospital, Næstved, Denmark
}

\begin{abstract}
Summary. The objective of the present study was to assess the prevalence of familial aggregation of Type 1 (insulin-dependent) diabetes mellitus among Danish families with a diabetic child aged 20 years or less and to compare epidemiological data for familial and sporadic cases. We attempted to identify all patients with Type 1 diabetes aged $0-19$ years in Denmark treated at paediatric departments or at departments of internal medicine. This comprises more than $98 \%$ of all patients with Type 1 diabetes in this age group. Patients were identified through the local diabetic out-patient registry and asked to complete a questionnaire regarding data on diabetes onset and family history. Of 1574 probands 1419 agreed to participate $(90.2 \%)$. Additional cases of Type 1 diabetes were found in 171 families $(12.8 \%)$. Of these 115 were parent-offspring affected families, and in 56 families at least two siblings had Type 1 diabetes and healthy parents. Significant correlation in age at onset of Type 1 diabetes in
\end{abstract}

concordant siblings was observed $(r=0.5, p=0.0004)$. Significantly more probands had an affected father with Type 1 diabetes than a mother affected $(p<0.0001)$. Heterogeneity in epidemiological characteristics was observed between familial and sporadic cases, i. e. familial index cases were younger at onset of the disease, their parents were younger at birth of the index case, and there was no difference in gender of familial cases in contrast to sporadic cases where significantly more males were found. Over a 4-year period (19861989) an increasing trend in incidence was observed. However, an increase in incidence compared to previous Danish data from the 1970s and 1980 s could not be demonstrated.

Key words: Type 1 (insulin-dependent) diabetes mellitus, nationwide population-based, familial prevalence, sporadic cases.
The aetiology of Type 1 (insulin-dependent) diabetes mellitus is poorly understood. Marked differences in its incidence between racial groups and countries have been reported $[1,2]$. Recent studies suggest that the difference is due to variation in the prevalence of common aetiological risk factors, either genetic or environmental, in the population [3, 4]. It has also been proposed that population variation in the prevalence of Type 1 diabetes susceptibility genes, rather than differences in environmental factors, is the primary determinant of the worldwide patterns of disease [5].

Descriptive studies of the relatives of individuals with the disease demonstrated familial aggregation of Type 1 diabetes [6-11], but attempts to define a specific mode of inheritance have been unsuccessful. Major genetic predis-

\footnotetext{
* The Danish Study Group of Diabetes in Childhood is an association of paediatricians with a special interest in diabetes research. For participating departments in the present study see Acknowledgements
}

position to Type 1 diabetes is conferred by the HLA class II specificities, but also non-HLA genes may confer susceptibility, and it was suggested that the frequency of Type 1 diabetes susceptibility genes is higher in families with affected individuals. In addition to the presence of Type 1 diabetes susceptibility genes, potential environmental factors are likely to cluster in these families.

Clearly, more information about genetic and environmental factors and the interaction between these factors is essential for preventive and interventive strategies aimed at the eradication of Type 1 diabetes.

Previous studies reporting prevalence of familial occurrence of Type 1 diabetes are not directly comparable, primarily because of methodological differences. Most of the study populations consisted of patients identified from specific hospitals or diabetes clinics $[6,10,12,13]$, and have rarely been studied in a nationwide and populationbased manner [14-16]. Within countries, family history information will permit (1) assessments of familial aggregation of the disease, (2) estimation of recurrence risks of 
Type 1 diabetes in families, (3) evaluations of the epidemiology of Type 1 diabetes in family members, and (4) identification of probands and families for genetic and immunological marker studies.

The population in Denmark is ethnically homogenous and the health care system well-organized, thus offering unique opportunities for epidemiological and genetic studies. The aim of the present study was to assess the prevalence of familial clustering of Type 1 diabetes among all families with a diabetic child aged 20 years or under in Denmark and to compare epidemiological data for the sporadic and familial cases.

\section{Subjects and methods}

\section{Patients}

No central registration of patients with Type 1 diabetes takes place in Denmark, thus the exact number of diabetic patients - children as well as adults - is unknown. In the present study we intended to identify and study all children with Type 1 diabetes attending a department of paediatrics or a department of internal medicine in Denmark. They had to be under the age of 20 years on 1 September 1990. According to epidemiological studies in Denmark [17] the number of diabetic children who are treated by general practitioners, by specialists in private practice, or who are not followed anywhere is very low $(<1 \%)$. From two previous nationwide studies in paediatric departments $[18,19]$ we knew that 1109 patients in this age group were attending 1 of the 22 paediatric departments in 1989. From records of paediatric departments we therefore needed to identify only patients with a diabetes onset from 1 January 1989 to 1 September 1990 and patients who had not been reported by the previous investigators $[18,19]$. No study has previously attempted to identify the diabetic children treated at departments of internal medicine in Denmark.

We asked all the paediatric departments to confirm our registration data from 1989 and to add new cases to the list. All the departments of internal medicine were asked to identify any diabetic children and adolescents they were treating. All the departments participated, and in each department one person was designated as the authors' contact person. This contact person made sure that all the cases were traced and reported. Of the 1109 patients previous registered (in 1989) 27 were now being treated in departments of internal medicine. Eighty-two patients were either incorrectly registered in 1989 (i.e. double or erroneously registered), emmigrated or had been referred to general practitioners by 1 September 1990. In addition 156 new cases were reported.

In departments of internal medicine 418 diabetic children and adolescents were known. Thus, a total of 1574 possible probands were identified.

Estimations of incidence are based on population statistics available from the Danish Government Bureau of Statistics [20].

\section{Methods}

Each patient was asked to complete a questionnaire at their local diabetic out-patient clinic. The questionnaire requested the following information: age, month and year of diabetes onset, age of mother, father and all siblings, gender of each sibling and whether the siblings were half-brothers/sisters or full-brothers/sisters. Finally we asked for the family history of diabetes in first degree relatives, and if relevant, the year of onset.

In relatives Type 1 diabetes was defined as onset of diabetes at age 35 or less and insulin requirement from time of diagnosis. If affected relatives were older than 35 years at onset of the disease the diagnosis was established on the criteria of their lean body weight and insulin requirement from diagnosis $(n=3)$.

The study was approved by the National Ethics Committee.

\section{Statistical analysis}

Results are expressed as mean \pm SD. For independent categorical variables, the chi-square test was used to compare proportions. The Mann-Whitney test was used to compare the medians of the two groups for independent continuous variables. In cases of multiple comparisons the $p$ values were corrected for the number of tests. Spearmann's test was used for testing significance of correlations. Life-table risk analysis was used to evaluate the occurrence risk of Type 1 diabetes in first degree relatives, including offspring to parents with Type 1 diabetes. The Jonckheere-Terpstra test was used to test for trend (one-tailed).

\section{Results}

A total of 1574 patients were identified. The questionnaire was completed by 1419 patients resulting in a participation rate of $90.2 \%$. Ten patients stated on the questionnaire that they did not wish to participate further and nine patients who were adopted, were unable to complete it. The male:female ratio was 1.13 (753: 665) $(p<0.001)$. The age of the probands was $14.4 \pm 3.8$ years (mean \pm SD), range: 1-19 years. Age at onset of diabetes was $8.6 \pm 4.2$ years, range: $0-19$ years. No difference was found between girls and boys.

Of the 1419 probands, 197 had at least one first degree relative with Type 1 diabetes, whereas 1164 were sporadic cases. Family histories of Type 1 diabetes were not obtainable in 58 cases: 10 probands refused to participate, 9 were adopted and in 39 cases the questionnaire was incomplete. Of the 197 familial cases, 26 were sibling-pairs, where both had completed a questionnaire, and thus the families were registered twice. The prevalence of familial Type 1 diabetes was calculated to $12.8 \%$.

Data for familial and sporadic cases are given in Table 1. The index case is defined as the first affected child from multiple-case families. A significant difference in gender was observed within the sporadic cases with more males $(p<0.001)$. In familial cases no difference in gender was observed. The age of probands was similar in the two groups. However, significant difference in age at onset of diabetes was observed between the groups. Age at onset in familial cases was $7.6 \pm 4.3$ years and $8.6 \pm 4.2$ years in sporadic cases $(p=0.01)$.

The age of parents at birth of probands in familial cases was lower than in sporadic cases: mothers $26.1 \pm 4.4$ years vs $27.4 \pm 4.8$ years $(p=0.0008)$ and fathers $28.4 \pm 4.9$ years vs $30.2 \pm 5.8$ years $(p=0.0003)$. The numbers of siblings were identical in the two groups: 1.4 sibling per proband. In 144 sporadic and 22 familial cases the proband was the only child $(p=0.7)$.

Seasonal variation in onset of diabetes was evaluated. No significant seasonal pattern was found either in sporadic cases or in familial cases (data not shown). Familial cases were further characterized as shown in Table 2. Ninety probands $(6.7 \%)$ had a father with Type 1 
diabetes, whereas $28(2.1 \%)$ had an affected mother $(p<0.0001)$. Sixty-seven probands $(5.0 \%)$ had a least one sibling with Type 1 diabetes. In total 17 probands $(1.3 \%)$ had more than one Type 1 diabetes-affected firstdegree relative. In addition, six probands had a mother and six probands a father with Type 2 (non-insulindependent) diabetes.

There was no correlation between age at onset of Type 1 diabetes in mothers or fathers and age at onset of the proband. There was no correlation between time at onset in diabetes-affected parents and probands. However, a significant correlation between age at onset between the first and second affected siblings was observed $(r=0.5, p=0.0004)$. Mean age at onset for the second affected sibling was $11.2 \pm 6.1$ years, being significantly higher than for index cases $(p=0.0002)$.

The point of onset of Type 1 diabetes in affected mothers was also evaluated in relation to time of birth of probands. In 19 cases the mother had been diagnosed with diabetes before and in 9 cases after the birth of the index case. The mean ( \pm SD) age of mothers with Type 1 diabetes at birth of proband was $24.6 \pm 3.6$ years.

The mean number of children born to mothers with Type 1 diabetes (1.96) was not significantly different from the mean number of children born to fathers with Type 1 diabetes (2.16). The male:female ratio of children born to diabetic fathers and diabetic mothers (108: 88 and 23:32) was also similar $(p=0.11)$. The proportions of children with Type 1 diabetes born to fathers with Type 1 diabetes and mothers with Type 1 diabetes were similar. No significant differences in the gender distribution by birth order were found. Children with Type 1 diabetes were more often first born to mothers with Type 1 diabetes, though this was not statistically significant, whereas no difference in birth order of affected children to affected fathers was observed.

Life-time risk analysis revealed no differences in risk of Type 1 diabetes to offspring of fathers with Type 1 diabetes or mothers with Type 1 diabetes during the short observation period (until 1 September 1990). The mean observation time for offspring at risk to affected fathers was $13 \pm 6.9$ years and for offspring at risk to affected mothers $15.5 \pm 7.7$ years.

We attempted to estimate the incidence for children aged 0-15 years in the period from 1986-1989 (Table 3). The denominator in the equation was the total number for the entire age range involved [20]. Incidence numbers were further divided into numbers for boys and girls.

\section{Discussion}

We have collected information on familial data from 1419 patients with Type 1 diabetes aged under 20 years by 1 September 1990 . This exceeds $90 \%$ of the patients in this age group known to attend hospital departments in Denmark for diabetes treatment. We know from previous studies, which validated hospital registries against the nationwide registry for which filing of data is mandatory for all institutions [17] (Nørgaard et al. unpublished data), that the registrations at the local hospital departments are
Table 1. Comparison of familial and sporadic cases of Type 1 diabetes

\begin{tabular}{lll}
\hline & Familial & Sporadic \\
\hline$n$ & 171 & 1164 \\
Male/female & $88 / 83$ & $624 / 540^{\mathrm{a}}$ \\
Age (years) & $14.7 \pm 3.6$ & $14.3 \pm 3.9$ \\
Age at diabetes onset (years) & $7.6 \pm 4.3$ & $8.6 \pm 4.2^{\mathrm{b}}$ \\
Mother's age at birth of proband (years) & $26.1 \pm 4.4$ & $27.4 \pm 4.9^{\mathrm{c}}$ \\
& $(n=167)$ & $(n=1142)$ \\
Father's age at birth of proband (years) & $28.4 \pm 4.9$ & $30.2 \pm 5.8^{\mathrm{d}}$ \\
& $(n=169)$ & $(n=1133)$ \\
Number of siblings & 1.4 & 1.4 \\
\hline
\end{tabular}

In familial cases with two or more affected offspring data are for the first affected child (index case).

${ }^{\mathrm{a}} p<0.001$, in sporadic cases (deviation from expected); ${ }^{\mathrm{b}} p=0.015$; ${ }^{\mathrm{c}} p=0.0008 ;{ }^{\mathrm{d}} p=0.0003 ;{ }^{\mathrm{b}, c, \mathrm{~d}}$ comparing familial vs sporadic cases (all $p$-values corrected).

Values shown are mean $\pm \mathrm{SD}$

Table 2. Affected first degree relatives of probands with Type 1 diabetes. Data are from 171 families

\begin{tabular}{lr}
\hline Affected fathers & 78 \\
Only the father & 7 \\
Father and one sibling & 2 \\
Father and two siblings & 2 \\
Father and mother & 1 \\
Father and mother and two siblings & 90 \\
Total & \\
Affected mothers & 24 \\
Only the mother & 1 \\
Mother and one sibling & 2 \\
Mother and father & 1 \\
Mother and father and two siblings & $28^{\mathrm{a}}$ \\
Total & \\
Affected siblings & 52 \\
One sibling & 4 \\
Two siblings & 8 \\
One sibling and a parent & 3 \\
Two siblings and a parent & 67 \\
Total & \\
\hline
\end{tabular}

${ }^{\mathrm{a}} p<0.0001$ vs fathers

Table 3. Estimation of trend in incidence numbers (cases per 100,000 ) in children aged 0-15 years from 1986-1989

\begin{tabular}{llll}
\hline Year & Total & Boys & Girls \\
\hline 1986 & 13.9 & 16.0 & 12.2 \\
1987 & 12.7 & 13.6 & 12.3 \\
1988 & 15.4 & 17.3 & 14.4 \\
1989 & 17.4 & 17.4 & 17.5 \\
Total & 14.8 & 16.1 & 14.1 \\
\hline
\end{tabular}

as complete as in the Central Registry (Landspatientregisteret) of the Danish Health Authority. Furthermore, it has been reported in previous studies from Denmark that approximately $1 \%$ of these patients are treated by general practitioners [17]. This percentage seems to have declined in recent years due to consensus between general practitioners, paediatricians and internists [21]. Thus, a poten- 
tial referral bias where multiple-case families were likely to be overrepresented is not likely in this cohort. Previous studies from paediatric departments had identified 1109 patients. We were able to identify all these patients in the present study. Thus, though we have no independent source to evaluate ascertainment, the results of the present study are taken as representative for the Danish population with Type 1 diabetes aged 20 years or less. Among sporadic cases (i.e. no first degree relatives with Type 1 diabetes) 144 were single children, for whom no sibling information was available. They are, however, considered "sporadic" in the present study.

The prevalence of families with more than one member affected with Type 1 diabetes was calculated as $12.8 \%$. This is comparable to recent data from nationwide incidence studies in Sweden and Finland [14, 15].

We observed a significant preponderance of males among probands, which is in agreement with most other reports $[14,15,17,22-24]$. However, this was only true for sporadic cases. We also observed significantly younger age at onset of Type 1 diabetes in familial cases. Very few studies have evaluated age at diagnosis between familial and sporadic Type 1 diabetes cases. In one study the same tendency was observed [7], whereas in another study [25] familial cases were found to be significantly older at diagnosis. Both studies had, however, much smaller numbers of multiple-case families than the present study. Furthermore, a significant correlation between age at onset of Type 1 diabetes in affected siblings was found, with the second affected child being 3.6 years older at onset of Type 1 diabetes than the first affected child. Taken together these observations indicate heterogeneity in Type 1 diabetes which might be due to differences in environmental or genetic components, or both in familial and sporadic cases.

In contrast to other studies $[17,22,23,26-28]$ we observed no statistical seasonal variation in onset of diabetes though more cases were diagnosed during autumn (September-November) and winter (December-February).

In the present study we observed that parents of probands in multiple-case families were significantly younger at time of birth of the index case compared to sporadic cases. An increased risk for children born at older maternal age has been reported where neither of the parents had diabetes [29, 30]. However, Warram et al. [31, 32] have reported an increased risk of Type 1 diabetes in the offspring of diabetic mothers aged 25 years or less. Interestingly, the mean age of diabetic mothers in the present study was 24.6 years (at time of delivery).

One of the most intriguing patterns of familial aggregation of Type 1 diabetes is the gender difference in the prevalence of parental diabetes. Diabetic children from families with one Type 1 diabetic parent (i.e. parent-offspring families) are significantly more likely to have an affected father than a mother with Type 1 diabetes [12-15, $25,33]$ which was also the case in the present study. The mechanism by which paternal Type 1 diabetes is more frequently transmitted remains poorly understood. Several explanations have been proposed, including an increase in spontaneous abortion of susceptible fetuses by mothers with Type 1 diabetes [12], maternal immunological toler- ance of fetuses to autoantigens of the beta cell [31,34], an increase of paternal transmission of HLA susceptibility genes [35], and genomic imprinting [36-38]. Genomic imprinting would be suspected if (a) offspring of fathers with Type 1 diabetes had a higher risk of developing Type 1 diabetes than offspring of affected mothers, and (b) there were no gender differences in the prevalence of Type 1 diabetes among children of affected parents of a given gender. The present data only partially support the hypothesis of genomic imprinting. However, this could be due to the short observation time for children at risk of developing Type 1 diabetes, and a longer observation time will provide more information. To address the question of genomic imprinting properly, prospective follow up studies of representative populations of offspring to individuals with Type 1 diabetes are needed. In addition, genetic studies and molecular analyses of susceptibility genes are needed to further explore the possible contribution of genomic imprinting to Type 1 diabetes susceptibility.

A trend for an increase $(p=0.09)$ in incidence for children aged $0-15$ years was observed during the period from 1986-1989. We cannot entirely rule out if this finding reflects more complete participation of probands with a more recent onset of diabetes. Furthermore, the very few patients who may have died after diagnosis but before 1 September 1990, are not included in these data. The incidence rate was in general higher for boys than for girls and increased for both sexes over the 4-year period. An exception was 1987 where a decrease in reported cases for boys was observed. The numbers are minimum numbers due to the study design - and demonstrate an increasing trend compared to previous incidence data for this age group in Denmark: 15.1 cases per $100,000(0-14$ years, 1980-1984) [17,39], though the average of 14.8 cases per 100,000 over the 4 years (1986-1989) was similar. Very recent data have found an incidence number of 21.5 cases per 100,000 for three counties in Denmark [40]. The sample size of that study comprised only approximately $15 \%$ of the population size in the present study making comparison difficult. In contrast to several other reports from different geographic areas $[22,23,40-44]$ there is no clear increase in Type 1 diabetes incidence in Denmark over the last two decades. This is in agreement with recent studies from Denmark $[39,45]$ which demonstrated an increasing trend for Type 1 diabetes that reached a maximum in the late $1970 \mathrm{~s}$.

Finally, this population-based cohort of young patients with Type 1 diabetes and their relatives will be important for future genetic marker studies, for which a DNA bank is being established, and for intervention studies in prediabetic subjects.

Acknowledgements. The colleagues and other staff members from the following departments are acknowledged for their help in identifying patients with Type 1 diabetes for the present study: Departments of Paediatrics at the following hospitals: Aalborg, Aarhus, Esbjerg, Glostrup, Herning, Hillerød, Hjørring, Hvidovre, Holbæk, Hvidøre, Kolding, Nykøbing F, Næstved, Odense, Randers, Roskilde, Rønne, Slagelse, Sundby, Sønderborg, and Viborg. Departments of Internal Medicine at the following hospitals: Aalborg, Aarhus Amtssygehus, Aarhus Kommunehospital, Bispebjerg, Esbjerg, 
Fakse, Fredericia, Frederikshavn, Grenå, Haderslev, Herning, Hillerød, Hjørring, Hobro, Holbæk, Holstebro, Horsens, Hørsholm, Kalundborg, Kjellerup, Køge, Kolding, Næstved, Nykøbing F, Nykøbing M, Odder, Odense, Randers, Ringkøbing, Ringsted, Silkeborg, Skive, Slagelse, Sønderborg, Svendborg, Thisted, and Viborg.

\section{References}

1. Diabetes Epidemiology Research International Group (1988) Geographic patterns of childhood insulin-dependent diabetes mellitus. Diabetes 37: 1113-1119

2. The WHO Multinational Project for Childhood Diabetes Group (1991) Familial insulin-dependent diabetes mellitus (IDDM) epidemiology: standardization of data for the DIAMOND project. Bull WHO 69: 767-777

3. Field LL (1988) Insulin-dependent diabetes mellitus: a model for the study of multifactorial disorders. Am J Hum Genet 43: 793 798

4. Thomson G, Robinson WP, Kuhner MK et al. (1988) Genetic heterogeneity, modes of inheritance, and risk estimates for a joint study of Caucasians with insulin-dependent diabetes mellitus. Am J Hum Genet 43: 799-816

5. Dorman JS, LaPorte RE, Stone RA, Trucco M (1990) Worldwide differences in the incidence of type I diabetes are associated with amino acid variation at position 57 of the HLA-DQ $\beta$ chain. Proc Natl Acad Sci USA 87: 7370-7374

6. Degnbøl B, Green A (1978) Diabetes mellitus among first- and second degree relatives of early onset diabetics. Ann Hum Genet 42: $25-47$

7. Jaworski MA, Colle E, Guttmann RD et al. (1980) Insulin dependent diabetes: a comparison of families with single and multiple affected siblings. Diabetologia 19:97-100

8. Gamble DR (1980) An epidemiological study of childhood diabetes affecting two or more siblings. Diabetologia 19:341-344

9. Wagener DK, Sacks JM, LaPorte RE, MacGregor JM (1982) The Pittsburgh study of insulin-dependent diabetes mellitus. Risk for diabetes among relatives of IDDM. Diabetes 31: 136144

10. Chern MM, Anderson VE, Barbosa J (1982) Empirical risk for insulin-dependent diabetes (IDD) in sibs. Further definition of genetic heterogeneity. Diabetes 31: 1115-1118

11. Cheta D, Dumitrescu C, Georgescu Met al. (1990) A study of the types of diabetes mellitus in first degree relatives of diabetic patients. Diabete Metab 16: 11-15

12. Warram JH, Krolewski AS, Gottlieb MS, Kahn CR (1984) Differences in risk of insulin-dependent diabetes in offspring of diabetic mothers and diabetic fathers. N Engl J Med 311:149-152

13. Tillil H, Köbberling J (1987) Age-corrected empirical genetic risk estimates for first degree relatives of IDDM patients. Diabetes 36: 93-99

14. Dahlquist G, Blom L, Tuvemo T, Nyström L, Sandström A, Wall S (1989) The Swedish childhood diabetes study - Results from a nine year case register and a one year case-referent study indicating that type 1 (insulin-dependent) diabetes mellitus is associated with both type 2 (non-insulin-dependent) diabetes mellitus and autoimmune disorders. Diabetologia 32: $2-6$

15. Tuomilehto J, Lounamaa R, Tuomilehto-Wolf E et al. (1992) Epidemiology of childhood diabetes mellitus in Finland - background of a nationwide study of type 1 (insulin-dependent) diabetes mellitus. Diabetologia 35: 70-76

16. Tuomilehto J, Podar T, Reunanen A et al. (1991) Comparison of incidence of IDDM in childhood between Estonia and Finland, 1980-1988. Diabetes Care 14: 982-988

17. Christau B, Kromann H, Andersen O et al. (1977) Incidence, seasonal and geographical patterns of juvenile-onset insulin-dependent diabetes mellitus in Denmark. Diabetologia 13: 281-284

18. Mortensen HB, Hartling SG, Petersen KE, The Danish Study Group of Diabetes in Childhood (1988) A nation-wide cross-sec- tional study of glycosylated haemoglobin in Danish children with type 1 diabetes. Diabetic Med 5: 871-876

19. Mortensen HB, Marinelli K, Nørgaard K et al. (1990) A nationwide cross-sectional study of urinary albumin excretion rate, arterial blood pressure and blood glucose control in Danish children with type 1 diabetes. Diabetic Med 7:887-897

20. Statistisk Arbog (Statistical Yearbook) 1991. Danmarks Statistik, Copenhagen

21. Sukkersyge. Organisation af unders $\emptyset$ gelse og behandling (1981) Sundhedsstyrelsen (National Board of Health), Copenhagen

22. Dahlquist G, Blom L, Holmgren G et al. (1985) The epidemiology of diabetes in Swedish children 0-14 years - a six-year prospective study. Diabetologia 28: 802-808

23. Joner G, Søvik O (1989) Increasing incidence of diabetes mellitus in Norwegian children 0-14 years of age, 1973-1982. Diabetologia 32: 79-83

24. Blohmé G, Nyström L, Arnqvist HJ et al. (1992) Male predominance of type 1 (insulin-dependent) diabetes mellitus in young adults: results from a 5-year prospective nationwide study of the 15-34-year age group in Sweden. Diabetologia 35: 56-62

25. O'Leary LA, Dorman JS, LaPorte RE et al. (1991) Familial and sporadic insulin-dependent diabetes: evidence for heterogeneous etiologies. Diabetes Res Clin Pract 14: 183-190

26. Gamble DR, Taylor KW (1969) Seasonal incidence of diabetes mellitus. BMJ 3: 631-633

27. Green A, Andersen PK (1983) Epidemiological studies of diabetes mellitus in Denmark: 3. Clinical characteristics and incidence of diabetes among males aged 0 to 19 years. Diabetologia 25: 226-230

28. Bingley PJ, Gale EAM (1989) Incidence of insulin dependent diabetes in England: a study in the Oxford region, 1985-6. BMJ 298: 558-560

29. Flood TM, Brink SJ, Gleason RE (1982) Increased incidence of type I diabetes in children of older mothers. Diabetes Care 5: 571-573

30. Wagener DK, LaPorte RE, Orchard TJ, Cavender D, Kuller LH, Drash AL (1983) The Pittsburgh diabetes mellitus study 3: An increased prevalence with older maternal age. Diabetologia 25: 82 85

31. Warram JH, Krolewski AS, Kahn CR (1988) Determinants of IDDM and perinatal mortality in children of diabetic mothers. Diabetes 37: 1328-1334

32. Warram JH, Martin BC, Krolewski AS (1991) Risk of IDDM in children of diabetic mothers decreases with increasing maternal age at pregnancy. Diabetes 40: 1679-1684

33. McCarthy BJ, Dorman JS, Aston CE (1991) Investigating genomic imprinting and susceptibility to insulin-dependent diabetes mellitus: an epidemiological approach. Genet Epidemiol 8: 177-186

34. Takemore T, Rajewski K (1984) Mechanism of neonatally induced idiotype suppression and its relevance for the acquisition of self-tolerance. Immunol Rev 79: 103-117

35. Vadheim CM, Rotter JI, MacLaren NK, Riley WJ, Anderson E (1986) Preferential transmission of diabetic alleles within the HLA gene complex. N Engl J Med 315: 1314-1318

36. Swain JL, Stewart TA, Leder P (1987) Parental legacy determines methylation and expression of an autosomal transgene: a molecular mechanism for parental imprinting. Cell 50:719-727

37. Hall JG (1990) Genomic imprinting: review and relevance to human disease. Am J Hum Genet 46: 857-873

38. Julier C, Hyer RN, Davies J et al. (1991) Insulin-IGF2 region on chromosome $11 \mathrm{p}$ encodes a gene implicated in HLA-DR4-dependent diabetes susceptibility. Nature 354: 155-159

39. Mølbak AG, Nørgaard K, Christau B, Kjær M, Nerup J (1987) Secular trend in the incidence of insulin-dependent diabetes mellitus in Denmark. Acta Endocrinol 115 [Suppl 289]: 48 (Abstract)

40. Green A, Gale EAM, Patterson CC, the EURODIAB ACE Study Group (1992) Incidence of childhood-onset insulin-dependent diabetes mellitus: the EURODIAB ACE study. Lancet 339: 905-909 
41. Patterson CC, Smith PG, Webb J, Heasman MA, Mann JI (1988) Geographical variation in the incidence of diabetes mellitus in Scottish children during the period 1977-1983. Diabetic Med 5: $160-165$

42. Burden AC, Hearnshaw JR, Swift PGF (1989) Childhood diabetes mellitus: an increasing incidence. Diabetic Med 6: 334 336

43. Soltész G, Madácsy L, Békefi D, Dankó I, the Hungarian Childhood Diabetes Epidemiology Group (1990) Rising incidence of type 1 diabetes in Hungarian children (1978-1987). Diabetic Med 7:111-114

44. Tuomilehto J, Rewers M, Reunanen A et al. (1991) Increasing trend in type 1 (insulin-dependent) diabetes mellitus in childhood in Finland. Analysis of age, calender time and birth cohort effects during 1965 to 1984 . Diabetologia 34: 282-287
45. Green A, Andersen PK, Svendsen AJ, Mortensen K (1992) Increasing incidence of early onset type 1 (insulin-dependent) diabetes mellitus: a study of Danish male birth cohorts. Diabetologia 35: 178-182

Received: 27 January 1993

and in revised form: 4 May 1993

Dr. F. Pociot

Steno Diabetes Center

Niels Steensensvej 2

DK-2820 Gentofte

Denmark 